\title{
Gaining Patient Input on Naming a Novel Patient-Reported Outcome Instrument in Chronic Weight Management
}

\author{
Heather Rozjabek ${ }^{1} \cdot$ John Fastenau ${ }^{1}\left[\right.$ D Samara Bennett ${ }^{2} \cdot$ Lydia Min-Joo Lee $^{2}$
}

Published online: 14 July 2020

(c) The Author(s) 2020

A patient-reported outcome (PRO) is a measure based on a report about a patient's health status and function that comes directly from the patient [1]. A PRO instrument is used to capture data from patients in clinical trials and clinical practice to evaluate their perspective and experience. Evidence generated on PROs is used by regulators, payers, employers, providers, and patients to inform clinical decision-making. A novel PRO instrument to help understand the importance of hunger, appetite, cravings, and satiety in chronic weight management was developed in a manner consistent with the United States Food and Drug Administration's PRO guidance [1].

The instrument measures the four eating concepts of hunger, appetite, cravings, and satiety while being clear, easy to answer, and easy for patients to recall. In order to better understand patients' definitions, experiences, and the importance of eating-related factors in chronic weight management, interviews with overweight and obese patients were conducted [2]. Patients defined the concept of hunger as the physical need to eat. Appetite was defined as the desire to eat, interest in eating, or the amount of food desired. Patients described satiety as a state of feeling comfortably full and satisfied after eating, and thought of it as the absence or opposite of hunger. Cravings are a desire, rather than a physical need, to eat a specific and typically unhealthy type of food. The concepts of satiety and hunger were considered physical factors that are related to the quantity of food consumed, whereas cravings and appetite were psychological factors that impact the choice of food. A conceptual model was developed to capture the hypothesized relationships among the four eating concepts and their influence on both food quantity and choice (Fig. 1). Participant feedback on

John Fastenau

JFastena@its.jnj.com

1 Janssen Global Services, LLC, 700 US-202, Raritan, NJ 08869, USA

2 Johnson \& Johnson Design, New York, NY, USA the model revealed that the concepts of hunger and cravings were easier to define, describe, and differentiate; however, all four concepts were deemed important in chronic weight management.

The four eating-related concepts can be challenging to describe in a patient-friendly manner, so the decision was made to include patients in the process of naming the novel PRO instrument to ensure that the name is meaningful to patients. This approach supports patient-focused drug development (PFDD) initiatives by including the patient's voice in drug development and evaluation [3]. Additionally, it is anticipated that selecting a name that resonates with patients will help increase their understanding, utility, and compliance with completing the instrument, which will be important since the novel PRO instrument was developed for use in clinical practice in addition to clinical research.

A two-step approach was utilized to name the instrument in a way that would resonate with patients. Stream I included a naming activity and internal validation; stream II focused on external patient validation. In stream I, the research team had an internal brainstorming session during which over 100 name options were drafted. After narrowing down this list to the top name choices following the research team's cocreation review sessions, regulatory and competitive due diligence was conducted to flag naming similarities or any potential for market confusion. Two rounds of naming recommendations took place to narrow down the options before external validation. The first round cut the field of names down to 10 , which was then narrowed down further in the second round to five names. The final five names for external validation were: (1) Daily Eats: Daily Eating Factors; (2) Quick TASTE: Triggers Associated To Eating; (3) DASH-C: Daily Index of Appetite, Satiety, Hunger, and Craving; (4) DINE 5Q: Drivers INfluencing Eating; (5) Eat Pulse: Diary of Eating Drivers.

Stream II sought patient validation to determine the best name for the new PRO instrument. Eligible participants were adults aged $\geq 18$ years who were overweight or obese, had 


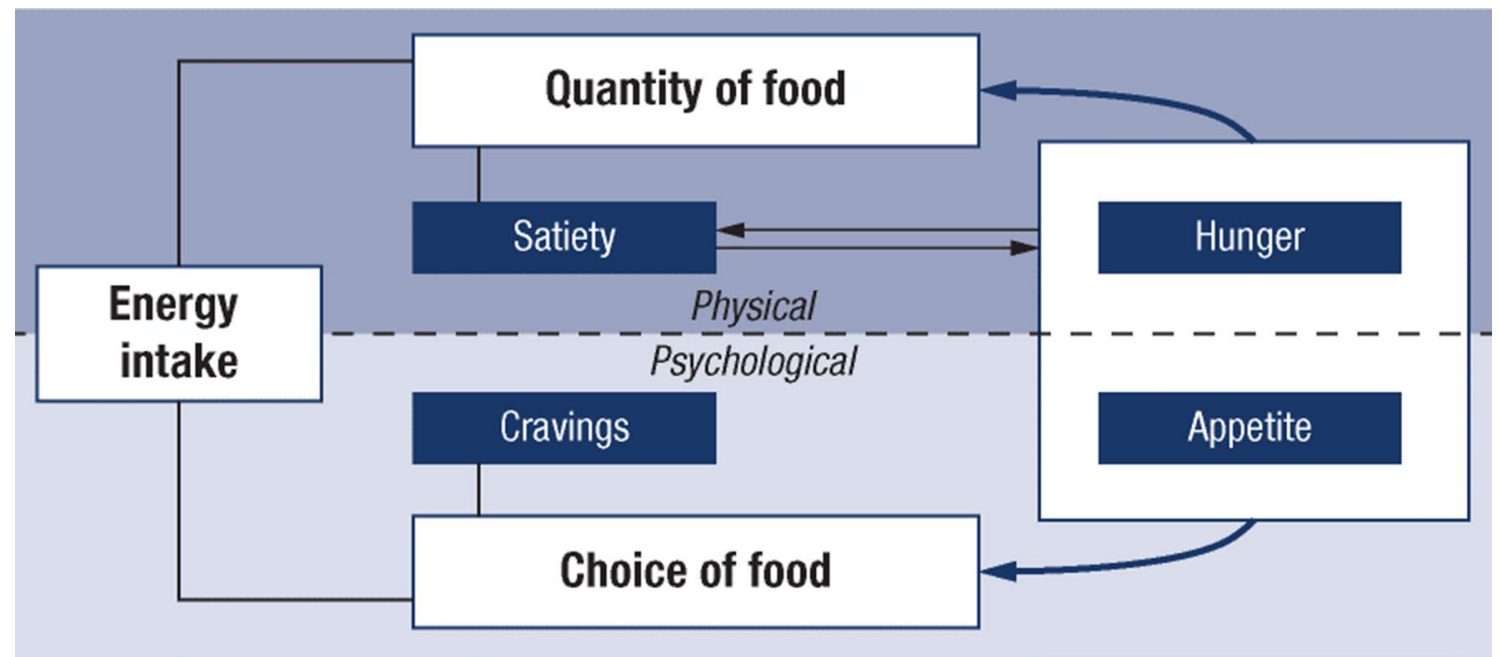

Fig. 1 Conceptual model of eating-related concepts in chronic weight management

attempted to lose weight in the past, and were able to read, speak, and understand English. Participants $(N=252)$ were recruited via a vetted, third-party online panel and qualified by a series of screening questions to match the aforementioned criteria. The 10-min study was conducted online (either by computer or mobile device) and fielded between November 28 through December 5, 2018.

Participants were first shown the instrument in order to understand the questions relating to the name options and to provide their individual perspective on how the name options related to the instrument. Each participant was presented with two name options ( $n \geq 100$ per name) and asked to rate each name based on five attributes (likeability, understanding, ability to recall, clarity, and fit with tool) using a fivepoint response scale (strongly agree, agree, neither agree nor disagree, disagree, strongly disagree) for each attribute. Each attribute was accompanied by a description to help ensure that participants understood it. "Likeability" was described as how appealing or unappealing the name was. "Understanding" referred to whether the name was easy to understand. "Ability to recall" was defined as whether the name was easy to remember and easy to recall. "Clarity" referred to whether the name clearly communicated what the tool was and how it was used. "Fit with tool" assessed whether the name related to the tool's purpose/use. The survey also collected feedback through open-ended text responses that allowed patients to describe what they liked and disliked about each of the attributes for each name option and then provide their own name suggestions.

To further validate the conceptual model of the four eating-related concepts, three additional questions were added to the survey: participants were asked to (1) rank the four concepts in order of importance for weight loss; (2) select the concept that plays the most important role in the amount or quantity of food they eat; and (3) choose the concept that has the greatest impact on their choice of foods. The Sterling Institutional Review Board determined that this study did not constitute human subject research and was exempt from review. All participants consented to the collection, use, and sharing of information captured in the online survey.

Of the 252 participants who completed the survey, the majority (59\%) were aged 25-54 years, 61\% were female, and $76 \%$ were Caucasian (Table 1). All participants were from the US, with the largest proportion being from the South (41\%), and $27 \%$ had obtained a bachelor's degree; $44 \%$ of participants had a BMI classified as obese class I, and $96 \%$ reported at least 1 previous weight-loss attempt. The results of the survey revealed that the name "Daily Eats: Daily Eating Factors" was overwhelmingly preferred. It ranked the highest for four of the five attributes: likeability, understanding, ability to recall, and clarity. The name "DASH-C: Daily Index of Appetite, Satiety, Hunger, and Craving" outranked "Daily Eats" on the fit with tool attribute, for which it was ranked second (Table 2). 
Table 1 Participant demographics

\begin{tabular}{|c|c|}
\hline Demographic characteristics & $\begin{array}{l}\text { Percentage of } \\
\text { participants } \\
(N=252)\end{array}$ \\
\hline \multicolumn{2}{|l|}{ Age (years) } \\
\hline $18-24$ & 6 \\
\hline $25-34$ & 21 \\
\hline $35-44$ & 24 \\
\hline $45-54$ & 14 \\
\hline $55-64$ & 18 \\
\hline $65+$ & 14 \\
\hline \multicolumn{2}{|l|}{ Sex } \\
\hline Female & 61 \\
\hline \multicolumn{2}{|l|}{ Race } \\
\hline Caucasian & 76 \\
\hline African American & 11 \\
\hline Asian & 4 \\
\hline Other & 2 \\
\hline \multicolumn{2}{|l|}{ Ethnicity } \\
\hline Hispanic/Latino & 11 \\
\hline \multicolumn{2}{|l|}{ Region } \\
\hline Northeast & 20 \\
\hline South & 41 \\
\hline Midwest & 19 \\
\hline West & 18 \\
\hline \multicolumn{2}{|l|}{ Education } \\
\hline Less than high school & 1 \\
\hline High school graduate & 23 \\
\hline Some college & 23 \\
\hline Associate degree & 12 \\
\hline Bachelor's degree & 27 \\
\hline Advanced degree & 10 \\
\hline \multicolumn{2}{|l|}{ Weight-loss attempts } \\
\hline Yes & 96 \\
\hline No & 4 \\
\hline \multicolumn{2}{|l|}{ BMI } \\
\hline Overweight (BMI 18.5-24.9) & 27 \\
\hline Obese class I (BMI 30-34.9) & 44 \\
\hline Obese class II (BMI 35-39.9) & 15 \\
\hline Obese class III (BMI $\geq 40)$ & 12 \\
\hline
\end{tabular}

${ }^{\text {a }}$ Percentages may not total 100 due to rounding
The open-ended feedback from participants for all five names was reviewed and taken into consideration before final name selection. The open-ended text responses received from participants varied between name options but included details such as specific terms that were difficult to understand, terms that resonated more to fit with the purpose of the instrument, and terms that were more appealing to participants, prompting a revision to be made to the final name. The Daily Eats concept was altered to "Daily Eats: Measuring Daily Eating Factors." The results from the three additional survey questions supported the conceptual model by finding an almost even distribution for the ranks of importance of the four eating concepts. Also, cravings, satiety, and hunger were most frequently reported to be the concepts with the largest influence on food quantity. Cravings had the largest influence on food choice (Fig. 2).

While patient participation has not previously been commonly sought when naming a new PRO instrument, patient input can provide a multitude of insights, and supports PFDD initiatives. Patients can identify phrases and terms that resonate most with them, and can select the name that will best explain the purpose of the instrument and help them to remember to complete it. In the current study, patient participants were engaged in the process of naming the novel PRO instrument Daily Eats: Measuring Daily Eating Factors. In addition to naming the instrument, this research supported the conceptual model of the importance of all four eating-related concepts in chronic weight management. In conclusion, this patient-centric approach to naming a novel PRO instrument identified a name that was clear and memorable to patients, which may increase interest and promote the utilization of the instrument in both clinical research and clinical practice. 
Table 2 Naming results scorecard

\begin{tabular}{|c|c|c|c|c|c|}
\hline Name options & Likeability & Understanding & Ability to recall & Clarity & Fit with tool \\
\hline (A) Daily Eats: Daily Eating Factors & $25 \%$ cDE & $36 \%^{\mathrm{DE}}$ & $33 \%^{\mathrm{BDE}}$ & $35 \%^{\mathrm{BCDE}}$ & $26 \%^{\mathrm{bDE}}$ \\
\hline (B) Quick TASTE: Triggers Associated To Eating & $23 \%^{\mathrm{DE}}$ & $27 \% \mathrm{DE}$ & $18 \%$ & $13 \%$ & $16 \%$ \\
\hline $\begin{array}{l}\text { (C) DASH-C: Daily Index of Appetite, Satiety, Hun- } \\
\text { ger, and Craving }\end{array}$ & $16 \%^{\mathrm{E}}$ & $31 \%$ DE & $29 \%{ }^{\mathrm{bDE}}$ & $20 \%{ }^{\mathrm{e}}$ & $29 \%^{\mathrm{BDE}}$ \\
\hline (D) DINE 5Q: Drivers INfluencing Eating & $9 \%$ & $12 \%$ & $13 \%$ & $14 \%$ & $15 \%$ \\
\hline (E) Eat Pulse: Diary of Eating Drivers & $6 \%$ & $10 \%$ & $15 \%$ & $11 \%$ & $14 \%$ \\
\hline
\end{tabular}

Each name option is represented by a letter, as denoted in column 1. Superscript letters indicate a significant difference between that option's metric and another option's metric. Upper- and lower-case letters signify $95 \%$ and $90 \%$ confidence, respectively. Options are sorted by likeability. Scores represent the percentage of participants who selected "strongly agree" on a 5-point scale. The top scores for likeability, understanding, ability to recall, clarity, and fit with tool are shown in italics. $N$ is at least 100 per option

A

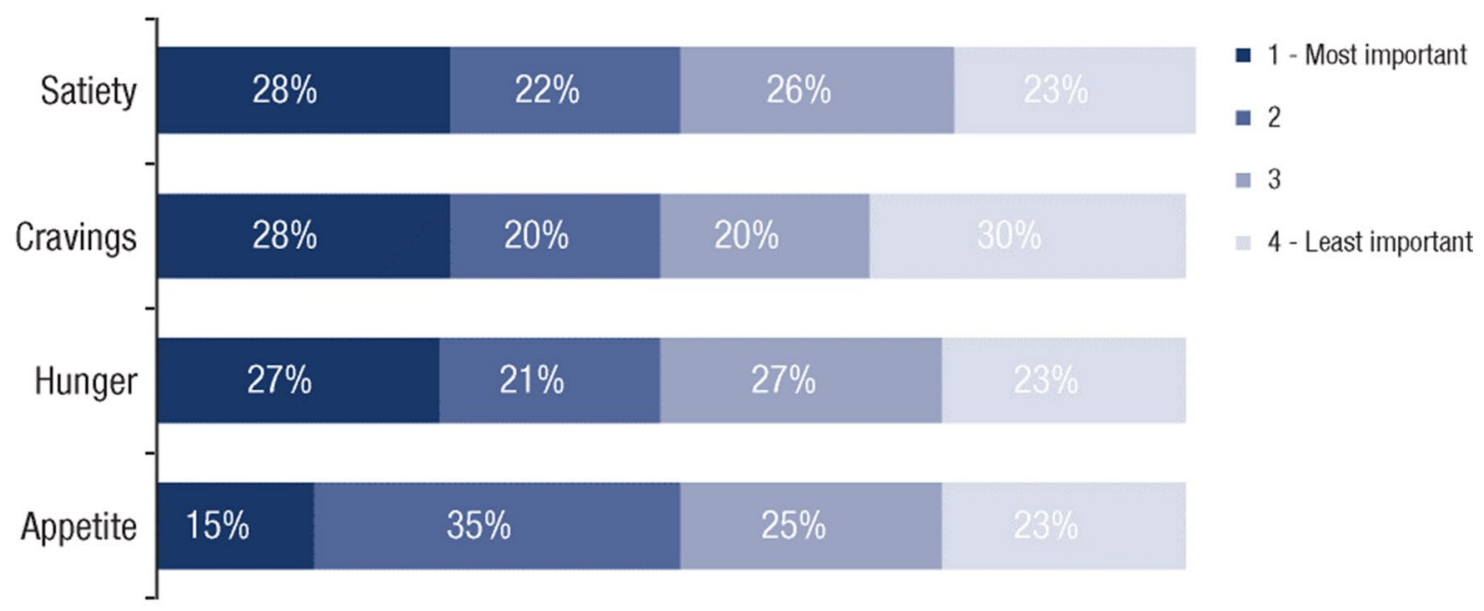

B

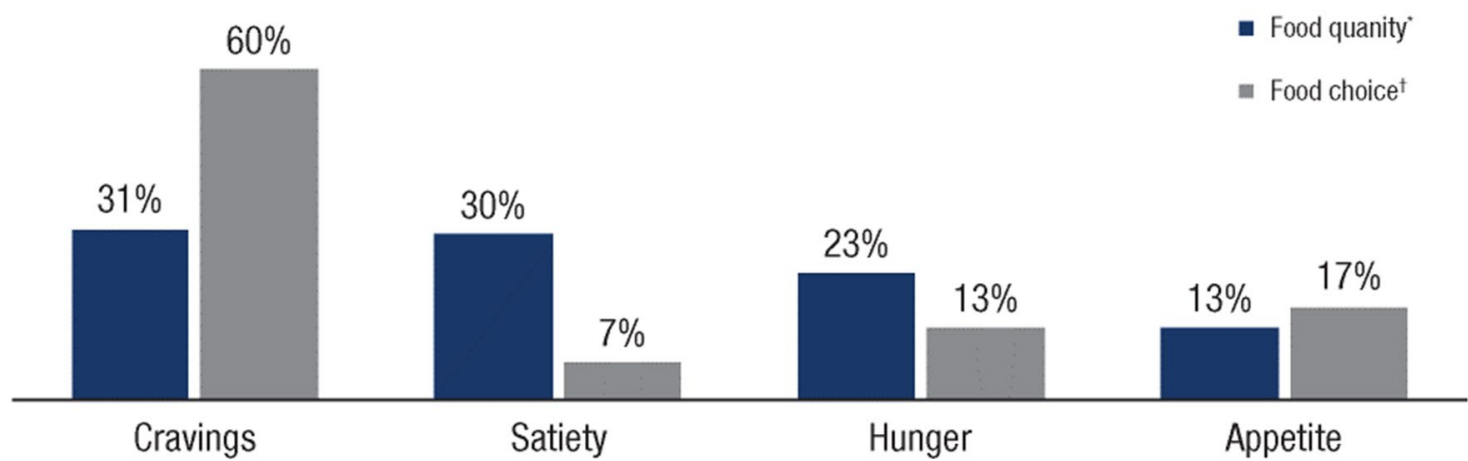

Fig. 2 Importance of the four eating-related concepts (a) and relation of each concept to food quantity and food choice (b) 
Acknowledgements This analysis was supported by Janssen Global Services, LLC. The authors wish to thank Lona Vincent of Johnson \& Johnson Design for her contributions to this study. Medical writing support was provided by Caryn Gordon, PharmD, of MedErgy, and was funded by Janssen Global Services, LLC.

Author contributions All authors were involved in the design and conduct of the study and the analysis and interpretation of the data, and they reviewed and approved the final manuscript.

Funding This study was supported by Janssen Global Services, LLC.

Availability of data and material The survey questionnaire used during the current study is available from the corresponding author on reasonable request.

\section{Compliance with Ethical Standards}

Conflict of interest HR and JF are full-time employees of Janssen Global Services, LLC. SB and LML are full-time employees of Johnson \& Johnson Design.

Ethics approval and consent to participate The Sterling Institutional Review Board determined that this study did not constitute human subject research and was exempt from review. All participants consented to the collection, use, and sharing of information captured in the online survey.

\section{Consent for publication Not applicable.}

Open Access This article is licensed under a Creative Commons Attribution-NonCommercial 4.0 International License, which permits any non-commercial use, sharing, adaptation, distribution and reproduction in any medium or format, as long as you give appropriate credit to the original author(s) and the source, provide a link to the Creative Commons licence, and indicate if changes were made. The images or other third party material in this article are included in the article's Creative Commons licence, unless indicated otherwise in a credit line to the material. If material is not included in the article's Creative Commons licence and your intended use is not permitted by statutory regulation or exceeds the permitted use, you will need to obtain permission directly from the copyright holder. To view a copy of this licence, visit http://creativecommons.org/licenses/by-nc/4.0/.

\section{References}

1. US Food and Drug Administration. Guidance for industry: patientreported outcome measures: use in medical product development to support labeling claims. Rockville: US Food and Drug Administration; 2009.

2. DiBenedetti D, Harris N, Rozjabek HM, Fastenau J. Assessing factors influencing eating in overweight and obese individuals. SAT103. Presented at: ENDO 2019; March 23-26, 2019; New Orleans, LA, USA. https://www.abstractsonline.com/pp8/\#!/5752/presentati on/18362. Accessed 4 Sept 2019.

3. US Food and Drug Administration. CDER patient-focused drug development. https://www.fda.gov/drugs/development-approvalprocess-drugs/cder-patient-focused-drug-development. Accessed 9 Mar 2019. 